GHANA JOURNAL OF DEPARTMENT OF HEALTH, PHYSICAL EDUCATION AND RECREATION, SPORTS AND DANCE (GJOHPERSD)

Volume 10, Year 2017

A JOURNAL OF THE DEPARTMENT OF HEALTH, PHYSICAL EDUCATION AND RECREATION (HPER)

UNIVERSITY OF CAPE COAST

GHANA, WEST AFRICA 


\title{
MAKING WEIGHT FOR SPORTS PERFORMANCE: IMPLICATIONS FOR HEALTH OF COMBAT SPORT ATHLETES IN NIGERIA
}

\author{
${ }^{* 1}$ Dominic, O. L., ${ }^{2}$ Talabi, A. E., ${ }^{3}$ Sarpong, E. O., ${ }^{4}$ Musa, M. O. \\ ${ }^{2}$ Seidina, I. Y., ${ }^{2}$ Abubakar, N. O. \& ${ }^{2}$ Bakinde, S.T. \\ ${ }^{1}$ Department of Health, Physical Education and Recreation \\ University of University of cape Coast, Ghana \\ ${ }^{2}$ Department of Human Kinetics Education, University of Ilorin, \\ Nigeria \\ ${ }^{3}$ Department of Health, Physical Education, Recreation and Sports, \\ University of Education, Winneba, Ghana \\ ${ }^{4}$ Federal College of Education, Okene
}

\begin{abstract}
The purpose of this study was to determine implication of weightmaking practice (WMP) on health of combat sport athletes. Descriptive correlational design was used. The population comprised 80 combat sports athletes who participated in Kongfu, Wrestling, Boxing, Judo, Karate and Taekwondo in Kwara State of Nigeria. Sixty-four (64) of them (age range $=15-54$ years; males $n=73.3 \%$ (44), weight $69.3 \pm 10.6 \mathrm{~kg}$ and females $n=26.7 \%$ (20), weight $61.5 \pm 11.6 \mathrm{~kg})$ were selected using stratified random sampling technique. Data was collected using a researcherdeveloped questionnaire, which was validated and tested for reliability $(r=.86)$. The SPSS version 20.0-application software was used for statistical analyses. Frequency counts and percentage were used to describe demographic data; mean and standard deviation were used for describing body composition. Chi-square was used to analyse the association between WMP and health, one-way ANOVA for the effect of sport on WMP and health. Hypotheses were tested for statistical significance at 0.05 alpha level. There was significant association between WMP and general health $\chi^{2}(1)=4.158, p=.034$; Cramer's $V=.27, p=.034$; odds $=1.2$. There was significant association between WMP and health
\end{abstract}


Dominic et al

after competition $\chi^{2}(1)=8.531, p=.003$; Cramer's $V=.38, p=$ .003 ; odds $=1.4$. There was no significant association between $W M P$ and health during competition $\chi^{2}(1)=2.347, p=.187$. Type of sport significantly influenced WMP, $F(5,58)=2.458, p=.004$, $\eta^{2}=0.228_{(22.8 \%) ;}$ general health $F(5,58)=4.240, p=.003, \eta^{2}=$ $0.185_{(18.5 \%) ;}$ and health after competition; $F(5,58)=2.597, p=$ $.035, \eta^{2}=0.194(19.4 \%)$. In conclusion, the participants' WMP may lead to physiological deviations and long-term health consequences. It was recommended that combat athletes and their coaches should be educated about the long-term effects of WMP on health and sports performance of athletes. Input of Exercise and Sport Scientists is vital for best practices in weight making.

Keywords: Combat sports, Health, Performance, Weight, Weight-making practice 


\section{Introduction}

Making weight is the practice used by weight class athletes to lose weight prior to competitive events in order to compete in a favourable weight category where they believe their chances of winning might be higher. As a basic rule in all combat sports, athletes must be classified according to their body mass, age and gender so that the matches are more equitable in terms of body size, strength and agility (Burke \& Cox, 2009; Langan-Evans, Close, \& Morton, 2011), to ensure fair and interesting matches as well as reducing the potential injuries caused by large differences in body mass and strength (Artioli et al., 2010). In order to achieve the target weight, many athletes use a combination of acute and chronic means that involves severe energy restriction and dehydration (Kons, Da Silva Athayde, Follmer \& Detanico, 2017). Dehydration is mostly used in the days preceding the weigh-in, a process commonly known in combat sports as "drying out" (Morton, Robertson, Sutton \& MacLaren, 2010). In addition, Langan-Evans et al. (2011) and Kons et al (2017) listed meal skipping, fasting, sauna use, sweat suits, laxatives use, diuretics, diet pills and vomiting as common approaches employed by combat sports athletes to make their desired weights. Pettersson, Ekstrom and Berg (2012), observed that delay in weigh-in till the match may allow acute recovery strategies, subsequent to severe food and fluid intake restrictions with dehydration associated with vigorous exercise done with sweat suits or saunas.

Many athletes acutely reduce body mass in an attempt to get an advantage by competing against lighter, smaller and weaker opponents (Artioli et al., 2010; Langan-Evans et al., 2011). The National Collegiate Athletic Association of Wrestling (NCAA) recommends weight loss not exceeding $1.5 \%$ total body weight per week. Similarly, Reale, Slater and Burke (2016) and Pallarés et al. (2016) noted that the American College of Sports Medicine, the Association of Ringside Physicians and the National Athletic Trainers Association warned against extreme practices. In fact, they recommended rule changes to discourage specific weight loss techniques and large magnitudes of acute weight loss (AWL) as well as recommended minimum body fat levels of $5 \%$ and $12 \%$ in 
males and females respectively. Unfortunately, many athletes including medalists exceed this limit in order to achieved better classification than those who lost less weight (Cicioglu et al, 2017). Thus, athletes who had practiced more aggressive weight cutting procedures presented better competitive results than their counterparts who were more conscious with their health (Reale et al, 2016; Cicioglu et al, 2017).

Evidence based studies have reported that athletes undergoing rapid weight loss (RWL), a process of $2-10 \%$ of body weight reduction over 5-7 days, have psychological issues like decrease in short-term memory, vigour, concentration and selfesteem as well as increased confusion, rage, fatigue, depression and isolation (da Silva Santos, Takito, Artioli \& Franchini, 2016). A drastic reduction in body weight before competition has been associated with alterations in basal metabolism, muscle glycogen, aerobic capacity, cardiac output, immunological system, cognitive problems, memory loss and poor information processing (Kons et al, 2017). These conditions are highly associated with performance impairments, delayed recovery from fatigue and might contribute to chronic health problems. Some epidemiological studies associated RWL with increased risk for injuries (Agel, Ransone, Dick, Oppliger \& Marshall, 2007), others found that a 5\% reduction in body mass affected metabolism and muscle contraction pattern, thereby increasing exposure to injury (Oopik et al., 1996; Green, Petrou, Fogarty-Hover \& Rolf, 2007).

Violation of weight making regulations continues to increase as athletes aim to perform better in competitions. According to Magraken (2014) several athletes have reportedly tested positive to diuretics, failed to make weight, and have withdrawn from contests due to adverse effects of weight cutting for example, nausea, vomiting, headaches, cramping, seizures, feinting and flu-like symptoms. It was reported in Spain, that weight making practice accounted for high prevalence of hypohydration among combat athletes at weigh-in, and this could not be fully reversed 13-18h before competition (Reale et al, 2016). In November 1997, three American wrestlers died during making weight using food and fluid restriction, vapour 

combat Sport Athletes in Nigeria impermeable suits and exercise in hot and humid environment (Magraken, 2014). Brazilian mixed martial arts (MMA) athlete, Leandro Souza also died in a sauna after attempting to lose $20 \%$

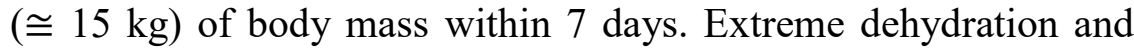
chronic use of non-steroidal anti-inflammatory drugs (NSAIDs) to lose weight has resulted in hospitalization of high-profile combat athletes some of whom were forced to retire prematurely with kidney disease (Crighton, Close \& Morton, 2015) or various levels of internal damages (Jenness, 2017).

While the benefits of weight making for performance remain equivocal, the practice is consistent among combat athletes. Currently, few researches have considered the implications of weight making on combat sport athletes in Nigeria. Hence, the need for the current study, which examined the practice among Nigeria combat sports athletes. Specifically, the study considered the association of weight making practice with general health of combat athletes, and their health during and after competition. The effect of type of combat sport, gender, age range, marital status and academic qualification on weight making practice was also examined.

\section{Methods}

The study was cross-sectional survey of 80 combat sports athletes who partook in wrestling, boxing, judo, kungfu, karate and taekwondo training at the Kwara State Stadium Complex. Stratified random sampling technique was used to select 64 of the athletes, which comprised 10 Kungfus, 11 Wrestlers, 10 Boxers, 10 Judokas, 12 Karate-Dos and 11 Taekwondoist. The sample was made up of $73.3 \%$ (44) males and $26.7 \%$ (20) females whose age range consisted of four decade groups; 15 to 24 years $(51.7 \%), 25$ to 34 years $(23.3 \%), 35$ to 44 years $(20.0 \%)$ and 45 to 54 years (5.0\%). In addition, 54.7\% (35) were single while 45.3\% (29) were married. Majority of the combat athletes had formal education as follows; $33.3 \%$ (20) secondary education, $23.4 \%$ (15) National Certificate of Education and National Diploma, 30.3\% (20) Bachelor degree, 3.1\% (2) Master degree and 10.9\% (7) had other type of education. The University of Ilorin Ethical 
Committee approved the study, all the participant were properly enlightened about the study and fully consented by filing and signing the informed consent form.

\section{Data Collection}

A validated researcher-designed questionnaire with two sections $\mathrm{A}$ and $\mathrm{B}$ was used to elicit information about weight making practice (WMP) and its effects on weight and health of the participants. Section A had seven items that elicited demographic information of participants. Section B had four sub-sections. Subsection (i) had 10 items on practice of weight making, (ii) had 10 items on effects of weight making, (iii) had 7 items on weight making and health implications during performance while (iv) had 5 items on after competition health implications. All the statements in section B followed a positive trend with scores assigned as follows; "Always" (4); "Often" (3); "Rarely" (2) and "Never" (1). For sub-section (i), the highest score was 40 and the lowest 10 . Sub-section (ii) was scored 40 as highest with 10 as the lowest. The status of the general effect of weight making was designated with the following cut-off points: (a) 1-20: no effect; (b) 21-40: very serious effect. Sub-section (iii) which covered the implications on athletes' health during performance had cut-off as follows: (a) 1-14: no effect on performance; (b) 15-28: totally affected performance. In sub-section (iv) the highest score was 20 and the lowest was 5. It covered the after competition health implications and had the following cut-off point: (a) 1-10: no after competition effect; (b) 11-20: serious after competition effect. Other instruments, standardized non-elastic anthropometric tape rule (Lufkin W606PM) was used to measure waist and hip circumferences (to the nearest $0.1 \mathrm{~cm}$ ) and body fat/hydration monitor scale (7032497, China) was used for measurement of body weight. Participants wore light clothing and removed their shows during measurements. Waist-to-hip ratio (WHR) was calculated as waist circumference divided by hip circumference. The ACSM (2013) health rating for waist circumference (WC) and WHR was used. WC was rated as follows: very low risk (female $=<70 \mathrm{~cm}$, male $=<80 \mathrm{~cm})$; low risk $($ female $=70-89 \mathrm{~cm}$, male $=80-99 \mathrm{~cm})$; 
high risk $($ female $=90-109 \mathrm{~cm}$, male $=100-120 \mathrm{~cm})$; and very high risk (female $=>110 \mathrm{~cm}$, male $=>120 \mathrm{~cm}$ ). WHR was rated as: desirable (female $=\leq 0.86$, male $=\leq 0.95$ ) and very high risk (female $=>0.86$, male $=>0.95$ )

\section{Data Analysis}

The SPSS version 20.0-application software was used for data analysis. Frequency count and percentage were used for analyses of demographic data, WC and WHR. Mean and standard deviation was used for analysis of body weight. Pearson Chisquare for independence was used to test the association between WMP and health. Cross tabulation with $2 \times 2$ contingency table were used to determine the proportion of association between the dependent and independent variables. To test for significant difference among the athletes, One-way ANOVA was conducted to examine the difference in WMP and its effect on their weight and health based on the type of sport they participated in. Marital status, gender, age range and educational qualification were considered as confounders and examined for their effects on WMP, weight change and implication for health. T-test was used to examine the effect of gender and marital status while One-way ANOVA was conducted to test the effect of age range, educational qualification. All tested hypotheses were considered to be statistically significant if $\mathrm{p} \leq 0.05$.

\section{Results}

Table 1: Descriptive Analysis of Body Composition of Combat Athletes

\begin{tabular}{lcll}
\hline Variable & $\begin{array}{c}\text { Mean } \pm \\
\text { SD }\end{array}$ & Frequency & Percentage \\
& & \\
\hline
\end{tabular}

\section{Weight}

Male $(\mathrm{n}=44) \quad 69.3 \pm 10.6$

Female $(\mathrm{n}=20) \quad 61.5 \pm 11.6$

\section{Waist}

Circumference

(WC)in cm 
Dominic et al

Male $(\mathrm{n}=44)$ 76.3 $\pm 16.5$

Female $(\mathrm{n}=20)$ $76.5 \pm 12.7$

Rating (Male and

Female)

Very low risk

Low risk

High risk

Waist-to-hip Ratio $\quad .84 \pm .08$

(WHR)

Male $(\mathrm{n}=44)$

$.86 \pm .11$

Female $(\mathrm{n}=20)$

Rating (Male and

Female)

Desirable (Low risk)

Very High risk

All the athletes reported they had engaged in practices of weight making to fit into certain combat category of the various sports and to improve their performances in competitions. These had impact on their body mass and body compositions. Table 1 shows descriptive analysis of the participants' WC and WHR. Average waist circumference for male participants was $76.3 \pm 16.5$ while that of female participants was $76.5 \pm 12.7$. Rating for health shows that $9.4 \%$ (6) had high risk WC that could predispose them to cardio-metabolic diseases. WHR indicated the male participants had an average of $.84 \pm .08$ and female participants had $.86 \pm .11$, the rating for disease risk shows that as much as $25 \%$ (16) participants had high risk for diseases. This implies WHR might be a more sensitive measure for detecting weight-related health risk among the participants.

Table 2: Association between Weight Making Practice (WMP) and Health of Combat Athletes 

combat Sport Athletes in Nigeria

\begin{tabular}{lllll}
\hline Variables & n & Value & df & Sig \\
\hline General Health & & & & \\
Pearson Chi-square $\left(\chi^{2}\right)$ & & 4.158 & 1 & .034 \\
Likelihood ratio & 64 & 4.656 & 1 & .031 \\
Cramer's V & & .27 & & .034 \\
& & & & \\
Health during Competition & & & & \\
Pearson Chi-square $\left(\chi^{2}\right)$ & & 2.347 & 1 & .184 \\
Likelihood ratio & 64 & 2.361 & 1 & .184 \\
Cramer's V & & .194 & & .126
\end{tabular}

\section{Health after Competition}

Pearson Chi-square $\left(\chi^{2}\right)$

Likelihood ratio

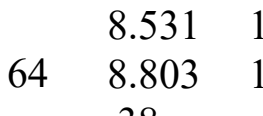

Cramer's V .38

$\mathrm{p} \leq 0.05$

The findings showed that WMP was associated with the participants' health. Based on the observed responses, $61.7 \%$ of the participants reported that WMP had no effect on their general health and health after competition while $38.3 \%$ of them reported serious effects. Pearson Chi-square test for independence (table 2) revealed a significant association between WMP and general health; $n=64, \chi^{2}(1)=4.158, p=.034$. The corresponding likelihood ratio was 4.656, $p=.031$. Overall, the effect of WMP on general health of these combat athletes was medium; Cramer's $V=.27, p=.034$. The odd that the participants would have any general health problems was 1.2 times due to the weight making practices they adopted. The association between WMP and the participants' health after competition was significant; $\mathrm{n}=64, \chi^{2}(1)$ $=8.531, p=.003$. The likelihood ratio for this association was $8.803, p=.003$; the size of health effect was medium Cramer's $V$ $=.38, p=.003$. Odds that WMP had effect on the athletes' health after competitions were 1.14 times. There was no significant association between WMP and the participants' health during competition; $\mathrm{n}=64, \chi^{2}(1)=2.347, p=.187$. 
Dominic et al

Table 3: Effect of Sport on WMP and Health of Combat Athletes

\begin{tabular}{lllllll}
\hline & & SS & df & MS & F & Sig \\
\hline $\begin{array}{l}\text { Effect on } \\
\text { WMP }\end{array}$ & $\begin{array}{l}\text { Between } \\
\text { groups }\end{array}$ & 2.630 & 5 & .526 & & \\
& $\begin{array}{l}\text { Within } \\
\text { Groups } \\
\text { Total }\end{array}$ & 11.554 & 58 & .214 & 2.458 & .004 \\
General & Between & 4.154 & 5 & .831 & & \\
health effect & $\begin{array}{l}\text { groups } \\
\text { Within }\end{array}$ & 10.580 & 58 & .196 & 4.240 & .003 \\
& $\begin{array}{l}\text { Groups } \\
\text { Total }\end{array}$ & $\mathbf{1 4 . 7 3 3}$ & $\mathbf{6 3}$ & & & \\
Effect during & $\begin{array}{l}\text { Between } \\
\text { groups }\end{array}$ & 1.619 & 5 & .324 & & \\
Within & 13.365 & 58 & .247 & 1.308 & .274 \\
& $\begin{array}{l}\text { Groups } \\
\text { Total }\end{array}$ & $\mathbf{1 4 . 9 8 3}$ & $\mathbf{6 3}$ & & &
\end{tabular}

Health effect $\quad$ Between $\quad 2.908 \quad 5 \quad .582$

groups

Competition Groups

$\begin{array}{lllll}12.092 & 58 & .224 & 2.597 & .035\end{array}$

$\begin{array}{ccc}\text { Total } & \mathbf{1 5 . 0 0 0} & \mathbf{6 3}\end{array}$

$\mathrm{n}=64 ; \mathrm{p} \leq 0.05$

Most of the athletes reported that WMP resulted in weight change. Table 3 shows the effect of sport on WMP and health of the participants. It was revealed that type of combat sport had significant effect on WMP; $n=64, F(5,58)=2.458, p=.004$. The size of this effect was large; $\eta^{2}=0.228_{(22.8 \%)}$, post-hoc analysis show that actual difference was among the taekwondo athletes; $M D=.616, p=.049,95 \% C I$ ranging from .002 to 1.234 and wrestling athletes; $M D=-.616, p=.049,95 \% C I=-1.234$ to .002. There was no significant difference in WMP of other 
athletes. There was a significant effect on general health; $n=64, F$ $(5,58)=4.240, p=.003$; the extent of this effect on the athletes was large, $\eta^{2}=0.185_{(18.5 \%)}$. Post-hoc analysis revealed two sports had the largest difference; boxing, $M D=.616, p=.035,95 \% C I=$ .028 to 1.204 and karate, $M D=.798, p=.002,95 \% C I=.210-$ 1.386. Furthermore, the type of sport had significant effect on health after competition; $n=64, F(5,58)=2.597, \mathrm{p}=.035$. This effect was also large, $\eta^{2}=0.194{ }_{(19.4 \%)}$; post-hoc result shows the effect was mostly observed among the taekwondo athletes; $M D=$ $.678, p=.024,95 \% C I=.056-1.315$ and karate athletes, MD = $.687, \mathrm{p}=.024,95 \% \mathrm{CI}=-1.315$ to -.059 . Our result showed type of combat sport had no significant effect on the athletes' health during competition; $n=64, F(5,58)=1.308, p=.274$.

Some variables: gender, age range, marital status and educational qualification considered potential confounders were analysed for effect on WMP, weight change, and health of the combat athletes. T-test analysis revealed no significant effect of gender and marital status on WMP, weight and health of the participants. One-way ANOVA revealed no significant effect of age range on WMP and health. However, the result shown in table 4 revealed that educational qualification of the athletes had significant effect on only their health after competition. $\mathrm{n}=64, \mathrm{~F}$ $(5,58)=4.930, p=.274$. The size of the effect was large $\eta^{2}=.264$ (26.4\%), and particularly differed among the most educated of the athletes. Post hoc analysis revealed that athletes who had bachelor degree $M D=.571, p=.003,95 \% C I=.155$ to .989 and those who had master degree had $M D=.737, p=.009,95 \% C I=-.203$ to 1.676 were significantly different from athletes with others forms of education.

Table 4: Effect of Educational Qualification on WMP and Health of Combat Athletes 


\begin{tabular}{lllllll}
\hline & & SS & df & MS & F & Sig \\
\hline $\begin{array}{lllll}\text { Effect on } \\
\text { WMP }\end{array}$ & $\begin{array}{l}\text { Between } \\
\text { groups }\end{array}$ & .875 & 5 & .219 & & \\
& $\begin{array}{l}\text { Within } \\
\text { Groups }\end{array}$ & 13.308 & 58 & .242 & .904 & .468 \\
& Total & $\mathbf{1 4 . 1 8 3}$ & $\mathbf{6 3}$ & & &
\end{tabular}

$\begin{array}{lllll}\text { General } & \text { Between } & 1.676 & 5 & .419\end{array}$

health effect groups

$\begin{array}{llllll}\text { Within } & 13.057 & 58 & .237 & 1.765 & .149 \\ \text { Groups } & & & & & \\ \text { Total } & \mathbf{1 4 . 7 3 3} & \mathbf{6 3} & & & \end{array}$

$\begin{array}{llllllll}\text { During Effect } & \begin{array}{l}\text { Between } \\ \text { groups }\end{array} & 1.624 & 5 & .406 & & \\ \text { Competition } & \begin{array}{l}\text { Within } \\ \text { Groups }\end{array} & 13.057 & 58 & .243 & 1.672 & .170 \\ & \text { Total } & \mathbf{1 4 . 7 3 3} & \mathbf{6 3} & & & \end{array}$

\begin{tabular}{lllllll} 
Health effect & $\begin{array}{l}\text { Between } \\
\text { groups }\end{array}$ & 3.959 & 5 & .990 & & \\
after & $\begin{array}{l}\text { Within } \\
\text { Competition }\end{array}$ & 11.041 & 58 & .201 & 4.930 & .002 \\
& $\begin{array}{l}\text { Groups } \\
\text { Total }\end{array}$ & $\mathbf{1 5 . 0 0 0}$ & $\mathbf{6 3}$ & & & \\
\hline
\end{tabular}

$\mathrm{n}=64 ; \mathrm{p} \leq 0.05$

Frequency distribution for health effect of WMP after competition indicated that among secondary school education level; $n=19$, no health effect $=26.3 \%$ (5) participants, very serious effect $=57.1 \%$ (14) participants. The NCE/diploma level was $n=14$, those who reported no health effect were $42.9 \%$ (6) participants, and very serious health effect were $57.1 \%$ (8) participants. The Bachelor degree holders $n=18,83.3 \%$ (15) participants reported no health effect, while very serious health effect were $16.7 \%$ (3). All the Master holders $n=2(100 \%)$ reported no health effect. Among participants who had other educational qualification $n=7$, only $28.6 \%$ (2) participants 
reported no health effect while $71.4 \%$ (5) participants had very serious health effect.

\section{Discussion}

The study was conducted to determine the implications of making weight on the health of combat athletes. Body composition assessment revealed the male athletes were heavier than the female athletes were. Body mass index (BMI) was not considered in analyzing body composition since it could be a misleading assessment for classifying athletes (Okorodudu, et al, 2010; Etchison, Bloodgood, \& Minton, 2011; Torstveit, \& SundgotBorgen, 2012; Buss, 2014), WC and WHR which are more consistent measurements in detecting body weight-related disease risk (Tagurum et al, 2015; Walther, Philipp, Lozza \& Ehlert, 2017) were used.

WC rating showed a few of the athletes $9.4 \%$ had high health risk while WHR indicated more of them $25 \%$ had very high health risk. This implies that WHR is a more sensitive measure for assessing the risk of overweight and obesity related diseases in combat athletes. Although this could be misleading as a number of studies have reported varying amount of sensitivity with the use of either WC or WHR for health assessment, some favoured WC (Oladapo et al, 2010) while others argued in favour of WHR (Odo, Ezeanyika \& Uchendu, 2015; Talabi, 2016; Walther et al, 2017). Based on the finding of this study, we suggest both measures are useful. Additional study following larger sample over time would better explain the most sensitive of these body composition measurements for weight-class athletes.

WMP alters metabolic activities, cardiovascular functions, electrolyte activity, thermo-regulation and renal function, that leads to decline in the ratio of fat mass (FM) to fat-free mass (FFM) and changes in total body water (TBW) (Sagayama, Yoshimura et al, 2014). This could affect the health of combat athletes (Langan-Evans, Close \& Morton, 2011; Sagayama et al, 2014; da Silva Santos et al, 2016; Kons et al, 2017) in several ways. Considering this, association of WMP with participants' 
health was assessed in the domains of general health (physiological and functional state every other day), health during (physiological and functional state while participating in competition), and after competition (physiological and functional state 24 hours up to 2 weeks after competition). This was quite different from other studies that mostly reported health effect of weight making without reference to periods before or after competition. Finding revealed no significant association between WMP and health of the participants during competition. In order to lose weight rapidly, some of the methods that combat athletes adopt include dehydration, fasting, skipping meals, laxatives and diuretics (Morton et al, 2010; Langan-Evans et al, 2011; Kons et al, 2017) that have impact on fuel supply, energetics and impairment of athletic performance (Dominic \& Onifade, 2005; Clark, Lucett \& Sutton, 2012; Papadopoulou, 2015). This have caused health problems such as poor blood circulation, anticipation skills, decision-making, cardiac arrhythmia, reduced bone mineral density and decreased muscle mass (Abedelmalek, Chtourou, Souissi \& Tabka, 2105; Chapman \& Woodman, 2016). During competitions, health status of athletes is crucial to their performance and is directly influenced by nutrition. It could be argued that WMP might have influenced the health of our participant in some ways, which they did not notice considering the fact that during competitions, athletes and coaches are mainly interested in winning and may easily attribute any physiological changes to demands of the competition. Similarly, Reale, Burke and Slater (2016) suggested that performance of a weight-class athlete is mostly considered relative to their opponents rather than the individual's absolute best, as such the effects of WMP practice on performance are often not known if the athlete have won an opponent.

WMP was significantly associated with the participants' health after competition and generally. In periods when the competitions were ended it is expected that recovery commences immediately with replenishment of depleted glycogen stores. However, practice of weight-making is reported to interfere with recovery due to compromised functions of organs and might lead 
to chronic health problems of various degrees (Jenness, 2017). In addition, chronic WMP resulted in energy deficits among athletes who use chronic weight loss and regain practices to manage their body mass leading to impairment in lean mass maintenance, immune function, bone health, metabolic and hormonal function (Franchini, Brito \& Artioli, 2012). This suggest a high tendency that combat athletes in Kwara State, Nigeria could have experienced symptoms of some of these health problems since it was found that they had health problems that affect their recovery after the competition and their health generally. It has been documented also that restriction of energy and nutrients compromises the immune system and decreased resistance to infection (Abdelmalek, Chtourou, Souissi \& Tabka, 2015), which also explains the health problems after competition and the extension to general health issues found in this study.

The type of combat sport participants engaged in had significant effect on their WMP; about $22.8 \%$ of the combination of methods adopted was determined by type of sport. This implied that athletes of each combat sport had unique WMP that they adopted to lose and regain weight. This finding confirmed previous studies that identified specific patterns of weight-making among different type of combat sport athletes (Andreato et al, 2014; da Silva Santos et al, 2016). The effect of sport on WMP was large and particularly highest among the taekwondo and wrestling athletes. Using a different protocol, some studies have shown that body mass gained between weight-in and success in competition suggest that apart from type of sport, the level of competition also have influence on WMP of combat athletes. For example, Reale et al. (2106) found that WMP of high school wrestlers was different from collegiate and national championship wrestlers. In addition, the number of competitions the athletes participated within the year might also account for variations in WMP since athletes always attempt to lose weight in order to fit into a desirable weight-class each time they compete (Kazemi, Rahman \& De Ciantis , 2011; Brito et al, 2012). As such, they are likely to try out a number of new methods to lose weight rapidly. There was significant difference in after competition and general health 
implication of WMP among the athletes. This further confirms our finding that WMP differed based on the type of combat sport of the participants. Regarding general health, type of sport accounted for a large difference of $18.5 \%$, which mostly affected the boxing and karate athletes. Similarly, WMP accounted for a large difference of $19.4 \%$ in after competition health among the athletes that affected mostly taekwondo and karate athletes. Since the type of sport affected WMP of the participants, it was expected that the same would be applicable to health during competition. Our finding however proved the type of combat sport did not significantly affect the participants' health during competition. This is in line with previous reports that RWL and WMP have negative consequences on health and performance of athletes during competitions (Reale et al, 2016; Cicioglu et al, 2017; Kons et al, 2017).

Among the hypothesized confounding variables (gender, age range, marital status and educational qualification), only educational qualification had significant effect on the participants' health after competition. Education is one of the factors that is strongly linked to health behaviours. Irrespective of socioeconomic status, people with higher level of education have increased positive health behaviours and better health status than those with lower education status (Feinstein et al, 2006; Çelebi, Gündoğdu \& Kızılkaya, 2017). This was confirmed in our study as it was discovered that high educational status significantly abated negative consequences of WMP on health after competition. Reported after competition health effect indicated that all the Masters holders had no health effect, just 3\% of the Bachelor degrees had health problems and $57.1 \%$ of NCE/Diploma and Secondary Education each had serious health effect. This suggest a need for nutritional and health enlightenment programme for the athletes in order to help them adopt healthy WMP that improve their performance and general wellbeing.

\section{Conclusions}

Based on the findings of this study we conclude that WMP influences health after competition and general health. This was specifically determined by type of combat sport and the level of 

combat Sport Athletes in Nigeria education of the athletes. For type of sport, the taekwondo, karate, wrestling and boxing athletes were most affected while those with lower levels of education (secondary and NCE/diploma) had more health problems. Despite proven competitive advantage of RWL, the long-term health implications may be deleterious if the athletes do not adopt healthy WMP. Therefore we recommend that:

1. Sports authorities in Nigeria should embark on enlightenment programmes to educate combat sport athletes and coaches about the long term hazards of RWL practices in order to prevent reduce the effect of prevailing practices and to abate unfortunate consequence during and after competitions.

2. Professionals in Exercise and Sport Science should help to proffer healthy alternatives for improving performance so that combat sports athletes and their coaches can avoid the use of rapid weight loss.

\section{References}

Abedelmalek, S., Chtourou, H., Souissi, N. \& Tabka Z. (2105). Caloric Restriction Effect on Proinflammatory Cytokines, Growth Hormone, and Steroid Hormone Concentrations during Exercise in Judokas. Oxidative Medicine and Cellular Longevity 3, 492-500.

Abedelmalek, S., Chtourou, H., Souissi, N. \& Tabka, Z. (2015). Caloric restriction effect on proinflammatory cytokines, growth hormone, and steroid hormone concentrations during exercise in judokas. Oxidative Medicine and Cellular Longevity, 1 - 9.

Agel, J., Ransone, J., Dick, R., Oppliger, R., \& Marshall, S. W. (2007). Descriptive epidemiology of collegiate men's wrestling injuries: National Collegiate Athletic Association Injury Surveillance System 1988-2004. Journal of Athletics Training, 42, 303-310.

Alderman, B. L., Landers, D. M., Carlson, J., \& Scott, J. R. (2004). Factors related to rapid weight loss practices among 
Dominic et al

international-style wrestlers. Medicine and Science in Sports and Exercise, 36, 249-252.

Andreato, L. V., Thaís Vidal Andreato, T. V., da Silva Santos, J. F., Del Conti Esteves, J. V., de Moraes, S. M. F., Emerson Franchini, E. (2014). Weight loss in mixed martial arts athletes. Journal of Combat Sports and Martial Arts 2(2), 125-131.

Artioli, G. G., Gualano, B., Franchini, E., Scagluisi, F. B., Takesian, M., Fuchs, M., \& Lancha, A. H. (2010). Prevalence, magnitude and methods of rapid weight loss among judo competitors. Journal of Sports Medicine and Exercise Science, 42, 436-442.

Artioli, G. G., Iglesias, R. T., Franchini, E., Gualano, B., Kashiwagura, D. B., Solis, M. Y... Lancha Junior, A. H. (2010). Rapid weight loss followed by recovery time does not affect judo-related performance. Journal of Sports Sciences, 28, 21-32.

Brito, C. J., Roas, A. F. C., Brito, I. S. S., Marins, J. C. B., Córdova, C. \& Franchini, E. (2012). Methods of body mass reduction by combat sport athletes. International Journal of Sport Nutrition and Exercise Metabolism 22, 89-97.

Burke, L. M., \& Cox, G. R. (2009). Nutrition in combat sports. In Combat Sports Medicine. $1^{\text {st }}$ edition. Edited by Kordi, R, Maffuli N, Woble R. R., \& Wallace, W. A. London: Springer- Verlag; 1-20.

Buss, J. (2014). Limitations of body mass index to assess body fat. SAGE Journals 62(6), 264 -264.

Çelebi, E., Gündoğdu, C. \& Kızılkaya, A. (2017). Determination of Healthy Lifestyle Behaviours of High School Students. Universal Journal of Educational Research 5(8), 12791287.

Chapman, J. \& Woodman, T. (2016). Disordered eating in male athletes: a meta-analysis. Journal of Sports Science 34(2), 101-109.

Cicioglu, H. I., Isik, O., Yildirim, I., Unveren, A. \& Karagoz, S. (2017). The effects of dehydration before competition upon 
Making weight for Sports Performance Implication for Health of combat Sport Athletes in Nigeria

body compositions, leptin hormone and ghrelin hormone among elite wrestlers. Biomedical Research 28(10), 43354341 .

Clark, M. A., Lucett, S. C. \& Sutton, B. G. (2012). Essentials of personal fitness training. National Academy of Sport Medicine (NASM) $\left(4^{\text {th }}\right.$ ed.). USA: Lippincott Williams \& Wilkins Baltimore.

Crighton, B., Close, G. \& Morton, J. (2015). Alarming weight cutting behaviours in mixed martial arts: a cause for concern and a call for action. British Journal of Sports Medicine $0(0), 1-2$.

da Silva Santos, J. F., Takito, M. Y., Artioli, G. G. \& Franchini, E. (2016). Weight loss practices in Taekwondo athletes of different competitive levels. Journal of Exercise Rehabilitation 12(3), 202-208.

Degoutte, F., Jouanel, P., Begue, R. J., Colombier, M., Lac, G., Pequignot, J. M., \& Filaire, E. (2006). Food restriction, performance, biochemical, psychological, and endocrine changes in judo athletes. International Journal of Sports Medicine, 27, 9-18.

Dominic, O. L. \& Onifade, A. O. (2005). Dietary attitude of University of Ilorin athletes. Ilorin Journal of Health, Physical Education and Recreation (IJOHPER) 4, 51 -56.

Etchison, W. C., Bloodgood, E. A., Minton, C. P. (2011). Body mass index and percentage body fat as indicators for obesity in an adolescent athletic population. Sports Health 3(3), $249-252$.

Feinstein, L., Sabates, R., Anderson, T. M., Sorhaindo, A. \& Hammond, C. (2006). Measuring the Effects of Education on Health and Civic Engagement: Proceedings of The Copenhagen Symposium. Retrieved November 2, 2017 from http://www.oecd.org/education/innovationeducation/37425753.pdf.

Filaire, E., Rouveix, M., Pannafieux, C., \& Ferrand, C. (2007). Eating attitudes, perfectionism and body-esteem of elite 108 
Dominic et al

male judoists and cyclists. Journal of Sports Science and Medicine, 6, 50-57.

Fleming, S. \& Costarelli, V. (2009). Eating behaviours and general practices used by Taekwondo players in order to make weight before competition. Nutrition and Food Science 39(1), 16-23.

Flemming, S., \& Costarelli, V. (2007). Nutrient intake and body composition in relation to making weight in young male Taekwondo players. Journal of Nutrition Science, 37, 358366.

Fogelholm, G. M., Koskinen, R., Laakso, J., Rankinen, T., Ruokonen, I. (1993). Gradual and rapid weight loss: Effects on nutrition and performance in male athletes. Journal of Sports Medicine and Exercise Science, 25, 371377.

Fogelholm, M. (1994). Effects of bodyweight reduction on sports performance. Journal of Sports Medicine, 18, 249-267.

Franchini, E., Brito, C. J. \& Artioli, G. G. (2102). Weight loss in combat sports: physiological, psychological and performance effects. Journal of the International Society for Sports Nutrition 9 (52), 1-6.

Franchini, E., Brito, C. J., \& Artioli, G. G., (2012). Weight loss in combat sports: physiological, psychological and performance effects. Journal of International Society of Sports Nutrition 9(1), 52

Green, O. M., Petrou, M. J., Fogarty-Hover, M. L. S., \& Rolf, C. G. (2007). Injuries among judokas during competition. Scandinavian Journal of Medicine and Sports Science, 17, 205-210.

Hoswill, C. A., Park, S. H., \& Roemmich, J. N. (1990). Changes in protein nutritional status of adolescent wrestlers. Journal of Sports Medicine and Exercise Science, 22, 599-604.

Jenness, K. (2017). MMA Fighter in Critical Condition. Retrieved November 26, 2017 from

http://www.mixedmartialarts.com/news/mma-fighter-incritical-condition. 

combat Sport Athletes in Nigeria

Kazemi, M., Rahman, A. \& De Ciantis, M. (2011). Weight cycling in adolescent taekwondo athletes. Journal of Canadian Chiropractic Association 55, 318-324.

Kons, R. L., Da Silva Athayde M. S., Follmer B, \& Detanico, D. (2017). Methods and magnitudes of rapid weight loss in judo athletes over pre-competition periods. Human Movement 8(2), 49-55.

Langan-Evans, C., Close, G. L., \& Morton, J. P. (2011). Making weight in combat sports. Journal of Sports and Exercise Science, 33(6), 25-39.

Magraken, E. (2014). Documenting the toll of rapid extreme weight cuts in MMA. Retrieved Janury 18, 2108 from http://combatsportslaw.com/2014/09/03/yes-athletes-havebeen-hurt-fromweight-cutting-in-mma/.

Morton, J. P., Robertson, C., \& MacLaren, D. P. (2010). Making weight: A case study from professional boxing. International Journal of Sports Nutrition and Exercise Metabolism, 20, 80-85.

Odo I., Ezeanyika U. \& Uchendu N. (2015). The relationship among body composition and body mass index in population of adolescents in Enugu State, Nigeria.

International Journal of Current Microbiology and Applied Sciences 4(1), 884-897.

Okorodudu, D. O., Jumean, M. F., Montori, V. M., et al. (2010).

Diagnostic performance of body mass index to identify obesity as defined by body adiposity: a systematic review and meta-analysis. International Journal of Obesity 34, 791-799.

Oladapo, O. O., Salako, L. Sodiq, O. Shoyinka, K., Adedapo, K. \& Falase, A. O. (2010). A prevalence of cardiometabolic risk factors among a rural Yoruba south-western Nigerian population: a population-based survey. Cardiovascular Journal of Africa 21(1), 26-31.

Oopik, V., Paasuke, M., Sikku, T., Timpmann, S., Medijainen, L., Ereline, J... Gapejeva, E. (1996). Effect of rapid weight loss on metabolism and isokinetic performance capacity. A 
case study of two well- trained wrestlers. Journal of Sports Medicine and Physical Fitness, 36, 127-131.

Pallarés, J. G., Martínez-Abellán, A., López-Gullón, J. M., MoránNavarro, R., De la Cruz-Sánchez, E. \& Mora-Rodríguez, R. (2016). Muscle contraction velocity, strength and power output changes following different degrees of hypohydration in competitive Olympic combat sports. Journal of the International Society of Sports Nutrition 13(10), 1-9. http//:dx.10.1186/s12970-016-0121-3.

Papadopoulou, S. D. (2015). Impact of energy intake and balance on the athletic performance and health of top female volleyball athletes. Medicina Sportiva 9(1), 2477-2481.

Pettersson, S., Ekstrom, M. P., \& Berg, C. M. (2012). The food and weight combat. A problematic fight for the elite combat sports athlete. Appetite, 59, 234-242.

Reale, R., Slater, G. \& Burke, L. M. (2016). Acute Weight Loss Strategies for Combat Sports and Applications to Olympic Success. Retrieved January 18, 2018 from https://www.researchgate.net/publication/304529333.

Saami, S. E., Rissanen, A., Sama, S., Koskenvuo, M., \& Kaprio, J. (2006). Weight cycling of athletes and subsequent weight gain in middle age. International Journal Obesity, 30, 1639-1644.

Steen, S. N., \& Brownell, K. D. (1990). Patterns of weight loss and gain in wrestlers: Has the tradition changed? Journal of Sports Medicine and Exercise Science, 22, 762-768.

Tagurum, Y. O., Okoh, O. E., Inalegwu, E., Ozoilo, J. U., Banwat, M. E. \& Zoakah, A. I. (2015).

Non-communicable diseases: Prevalence and risk factors among adults in a rural community in Plateau State, Nigeria. International Journal of Biomedical Research 6(04), 228 234. http://dx.doi.org.10.7439/ijbr

Talabi A. E. (2016). Heaven is far - only the fit can make it. Retrieved March 28, 2016 from http://www.unilorin.ng 

combat Sport Athletes in Nigeria

Torstveit, M. K. \& Sundgot-Borgen, J. (2012). Are under- and overweight female elite athletes thin and fat? a controlled study. Medicine \& Science in Sports \& Exercise, 949 -957.

Walther, A., Philipp, M., Lozza, N. \& Ehlert, U. (2017). Emotional support, depressive symptoms, and age-related alterations in male body composition: cross-sectional findings from the men's health 40+ study. Front. Psychol. 8, 1075. http://dx.doi.org.10.3389/fpsyg.2017.01075.

Webster, S., Rutt, R., \& Weltman, A. (1990). Physiological effects of a weight loss regimen practiced by college wrestlers. Journal of Sports Medicine and Exercise Science, 22, 229234.

Wroble, R. R., \& Moxley, D. P. (1998). Weight loss patterns and success rates in high school wrestlers. Journal of Sports Medicine and Exercise Science, 30, 625-628. 